\title{
PANOTS + MOSAICS: \\ Crafting Expression Through Hydraulic Cement
}

\author{
JONATHAN RULE \& ANA MORCILLO PALLARES \\ University of Michigan
}

The paper intends to reflect on the developmental trajectory of a research project that explores a dialogue between industrial Spanish modernist tile making and new approaches to fabrication through the emergence of new technologies. The juxtaposition of these two methods of production became the catalyst for the subsequent experimental technique that hybridizes hand-made, industrial hand-made and digital hand-made under the rubric of crafting expression through material technologies and hydraulic cement.

\section{INTRODUCTION}

The way we work and make is constantly evolving and being reshaped. Recently, this evolution has been marked by the reinterpretation of craft methods of production. The use of emerging technology juxtaposed with the application of "conventional" or craft materials allow for new territories of exploration that before were not possible. The research described in this article looks at the use of the mosaic in architecture and the development of a renewed interest in tectonic expression, material properties, and the ability to produce desired surface and spatial effects. The mosaic encompasses a long trajectory from its hand made beginnings to becoming a more industrialized process during the nineteenth century followed by current trends in digital making and the digital hand made.

Originating in Barcelona in 1857, the inlaid colorful geometric abstractions (Mosaics) and the variety of embossed shapes (Panots) allow for a wide range of nested geometries and depth that generate a formal field condition within the limitations of a horizontal surface. The baldosa hidraulica or hydraulic cement tile was a revolutionary process that combined craft technique with innovations in industrial fabrication fueled by the advent and wide spread use of Portland cement. Their production eliminated the need for firing to harden them, which consequently led to their exportation and fabrication throughout Europe and Latin America. A recent resurgence in their use has led to a renewed interest in this almost forgotten industrial craft. This renewed interest in researching preservation and the study of past craft techniques became a point of departure for the development of experimental and alternative methods of fabrication based on new technologies and composite materials. The objective of the research was not to recreate a construction material through true and tested methods but to re-examine the physical properties of the material, the processing and its intersection with new approaches to making as an opportunity to explore alternative territories for fabrication and the reinvention of artisanship in the digital era in the form of 'digital hand-made'.1

The research settled on the architectural surface and more specifically the technique of ornamenting or crafting expression through the mosaic. The use of the mosaic in architecture can be highlighted within the context of three key moments that mark a shift in how they were produced: their hand made beginnings, the transition to becoming a more industrialized process, and lastly, current trends in the digital hand made where we offer our project as a speculative future in mosaics.

\section{HAND-MADE}

In order to understand the origin of the industrially fabricated hydraulic cement tile it is important to contextualize it historically with respect to its predecessor the hand made mosaic floor pattern. The history of the mosaic is lengthy with some of the earliest excavated remains dating back more than five thousand years ago. The technique of arranging stones, pebbles, shells and glass, known as tesserae, into intricate patterns became more sophisticated over time and expanded throughout the Hellenistic period followed by the wide spread expansion of the Roman Empire around the Mediterranean region. The Roman and Byzantine periods established an empire wide trade of materials mainly consisting of marble and granite which were predominantly used in the making of these floors.

Over time these surfaces developed from what might be considered superficial decoration to an element that shaped the experience of space through the articulation of the ground plan. The floor pattern has the ability to structure space through "integral ornament" which Frank Lloyd Wright defines as "the developed sense of the building as a whole, or the manifest abstract pattern of structure itself...structure-pattern made visibly articulate. ${ }^{\prime 2}$ In the case of the many handcrafted floors found throughout the Roman Empire, the 


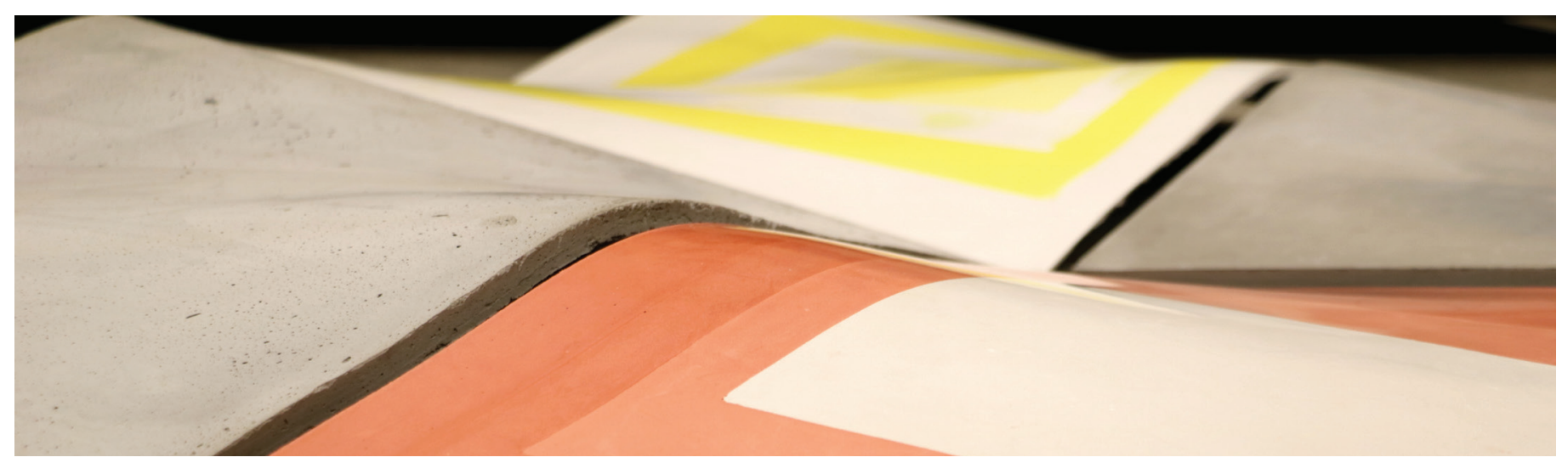

Figure 1: Cement panel tests (Morcillo Pallares, Rule, 2016)

"structure-pattern" is revealed through the use of the mosaic tile and its ability to articulate architectural space. The tiles in many cases transcend the ornamental to support the architecture through scale, movement, color and texture. A mosaic pattern has the ability to scale up or scale down architecture, provide continuity of movement through a space or signify a transition through a break in a continuous pattern.

Their predominant use as a ground surface and the intensive labor involved in crafting the hand made mosaics required the use of materials that were capable of withstanding the test of time. The desire for permanence exuberated by these early cultures was achieved through the process of embedding small pieces of stone and glass of various colors set in mortar to fix them in place. The artisanal in situ process for creating these intricate surfaces was extremely laborious and therefore could not rely on colors applied to a surface with a brush. Their survival required that they be more than skin deep. The influx of this technique in the Mediterranean region along with the desire for an embedded and long lasting material is paramount to understanding the development of the modern cement mosaic tiles. The literal thickening of the pattern along with the desire to mass-produce intricate surface patterns are essential characteristics that gave rise to the advancement and development of mosaics from a hand made technique to a 'standardized' and industrialized building material.

\section{INDUSTRIAL HAND-MADE}

Mechanization and industrial methods of making would mark an important change in the production mosaics. In addition, the advent of new materials, such as modern day cement invented in 1824 by Joseph Apsdin would lead to new products for the construction industry. First introduced at the 1864 Paris Worlds fair, cement tiles from the Catalonian region of Spain known as panots and mosaics were efficient new materials that artfully combined craft labor and industrialized making.

These industrially crafted cement tiles became prolific during the rise of Modernismo, the Spanish version of Art Nouveau. The technique presented a much more affordable method of making tiles in comparison to the handmade ceramic mosaic and allowed Spanish architects such as Domenech i Montaner and Antoni Gaudi to efficiently draw patterns with cement that allowed for more complex designs to enrich their architecture.

The manufacturing process consists of a combination of three distinct layers fused through compression and takes approximately 3-5 minutes to produce depending on the detail of the pattern desired for the finish surface. The first layer or finish layer (capa fina) consists of a mixture of white cement, marble dust, pigmentation and water that is mixed to a liquid consistency. This layer is poured into a standardized tile mold containing a secondary brass mold (trepa), which is used to separate the different colors of pigmented cement. Once all the colors have been poured, the trepa is removed and the second layer is added. This layer consists of a dry mix containing four parts cement and one part sand sprinkled onto the layer of pigmented cement as a way to absorb the excess water and fix the colored cement pattern in place. The final layer or backing layer (capa grueso) contains a ratio of four parts course sand, one part cement and a very small amount of water. The excess material is removed using a scraper (rasquillo), which ensures a consistent depth of material. Once the back of the tile is even that mold is covered with the 'tapa' and placed into a hydraulic press where a force of 30 tons is exerted onto the material. This pressure forces the layers together, eliminating air pockets and creating a solid bond. Lastly, the mold is removed from the press and the tile is removed from the mold and left to dry for twenty-four hours.

\section{DIGITAL HAND-MADE}

The industrial processes that revolutionized the method of making mosaics can be seen as analogous to todays influx of new technologies which have set up yet another possibility for new methods of making. New forms of craft once again orient themselves towards the past where a dialectical train of thought yields new results through the synthesis of analogue and digital methods of making. According to Glenn Adamson in his book, 'The Invention of Craft', "Craft demands proximity- the material to the maker, the tool to the work." While digitalization, "transforms and speeds up not only the flow of information, but also the production of material things and their subsequent movement. It inaugurates a completely new spatial logic." ${ }^{3}$ With this in mind and as a way to further probe the making of panots and mosaics, the research began by questioning the possibilities of applying this "industrial hand-made" craft to the digital. 


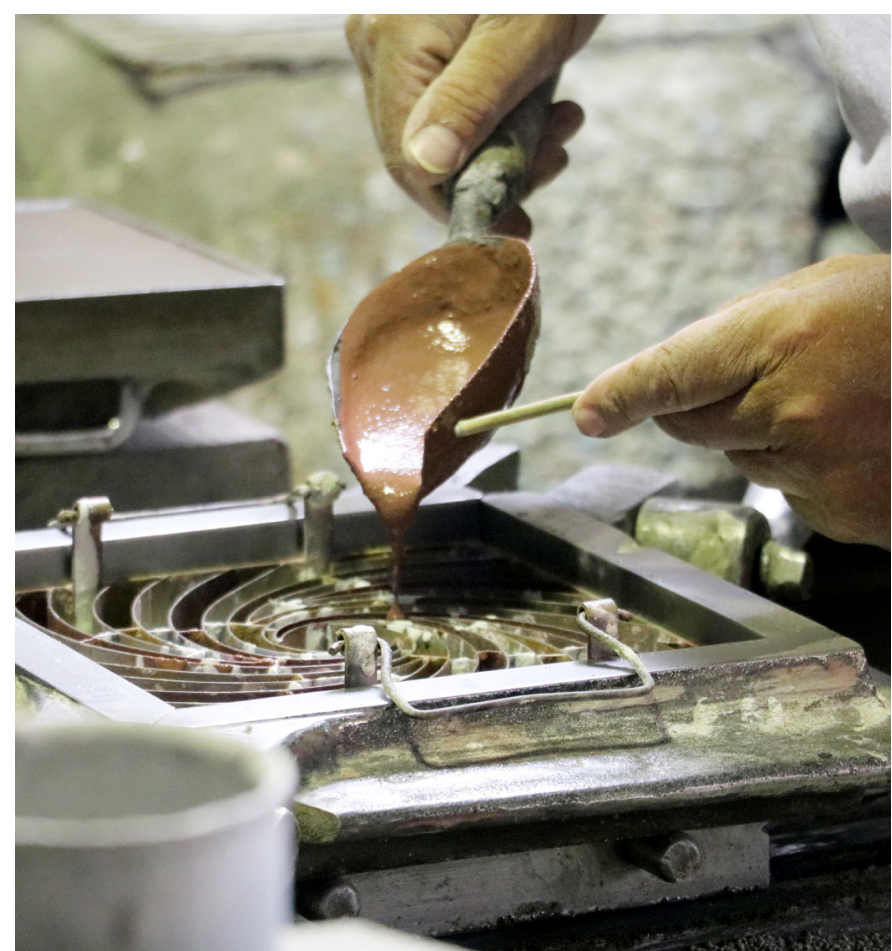

Figure 2: Industrial hand-made mosaic tile, Mosaics Marti (Morcillo Pallares, Rule, 2015)

The rise of digital fabrication led by 'digital artisans' posits new technologies alongside traditional tools where Lucy Johnston argues that we can find the creation of "products of exceptional quality that retain the soul of the material and the skill of the human hand, while also benefitting from the precision, efficiency and increasingly unrestricted structural parameters of digital design and fabrication." As a way to further explore recent developments and research in dynamic formworks for the production of concrete panel systems, the research focused on the hybridization of these digitally controlled formworks with the handcrafted skill of mosaic tile making from the nineteenth century. The goal was to develop a concrete panel system that contained the complex patterns of the mosaic embedded in a controlled complex geometric surface.

In the 1960's, Spanish architect Miguel Fisac began to experiment with a method known as the encofrado flexible or flexible formwork for the 'skin' of the building. "Architecture is limited space and as such it needs a material limitation, and this, just like our own bodies, must have a skin." ${ }^{5}$ For Fisac the concrete skin he was developing needed to be expressive and capture the genetic biometrics and 'retain the soul of the material' as a way expose its plasticity. Through a more artisanal and craft approach using a wood frame, transparent polyethylene sheets and string, Fisac was able to develop a simple reconfigurable and flexible formwork that would allow for the production of a complex embossed concrete panel system. The use of this system is first seen in 1969 in the design and construction of the Hospital de Dia de Fraternidad Muprespa in Madrid.

At the same time, Renzo Piano was also experimenting with a dynamically controlled formwork known as the 'Stampo deformabile, ${ }^{6}$ which resulted in the first controlled and practical application of a double curved surface. The formwork used a grid of actuators that would define a curve, which was used as the mold to cast a fiber-reinforced plastic panel for a small pavilion.

Since the work of Fisac and Piano the growing number of panelized facades and the use of complex geometries in architecture has led to intensive research in digitized manufacturing of dynamic formworks as a way to more economically produce these complex surface geometries. In this ongoing process of making, the hand made mosaic, the industrial hydraulic tile, and the twenty-first century investigations on the precise control in the production of double curved concrete surfaces have led us our project 'Panots \& Mosaics' which intended to build on these previous studies with a focus on the introduction of embedded color patterns in the curved cement panels.

The research chose to focus on the first layer of the Mosaic as a lighter and more efficient framework to develop a series of panels no longer limited to the ground surface and embedded with color. Borrowing the plasticity uncovered in Fisac's work and the digital frame of Piano, the result demonstrates a state which is not associated with this material or technique.

In an attempt to draw a parallel between the past and the contemporary, we began with the development of tools for the production of our doubly curved mosaics. Using as a reference the hydraulic cement tile, the work started by first trying to reproduce the tiles using the industrial method of production as a way to understand the materials properties and limitations. With an understanding of the limitations we were able to determine what parts of the original tile making process would be possible to maintain and allow for new possibilities in the materials manipulation. In a second phase, we began to introduce new materials such as rubber molds and super plasticized glass fiber reinforced cement to introduce a degree of flexibility within the cast pieces. In a final phase, the research took an approach to tooling, which Glenn Adamson defines as, "the making of the objects that go on to make other objects." 7 For this, a dynamic formwork was designed that would allow for a synthesis combining the industrial process for making mosaics with our desire to freely modify their form digitally. With the aid of Arduino micro-controller open source hardware and software along with the Firefly plugin for grasshopper a mold was developed that would establish a real-time connection between the digital and the physical world. For this initial prototype the mold was limited to the production of ruled surfaces using five ruling lines connected to ten stepper motors (two motors per line). The ruling lines were interconnected using flexible cast urethane foam matt and an interchangeable abrasion-resistant rubber sheet that would average the curve between each ruling line. The integration of Firefly allowed for the projection of ten digital points, one for each motor, onto a digitally modeled surface with the same footprint as the physical mold. The registration of these projected points in digital space were then precisely transferred to the geometry of the physical mold to define the final shape of the tile.

Through this new tool our research established a parallelism between the industrial handmade method of the mosaic and a new digital version. By 

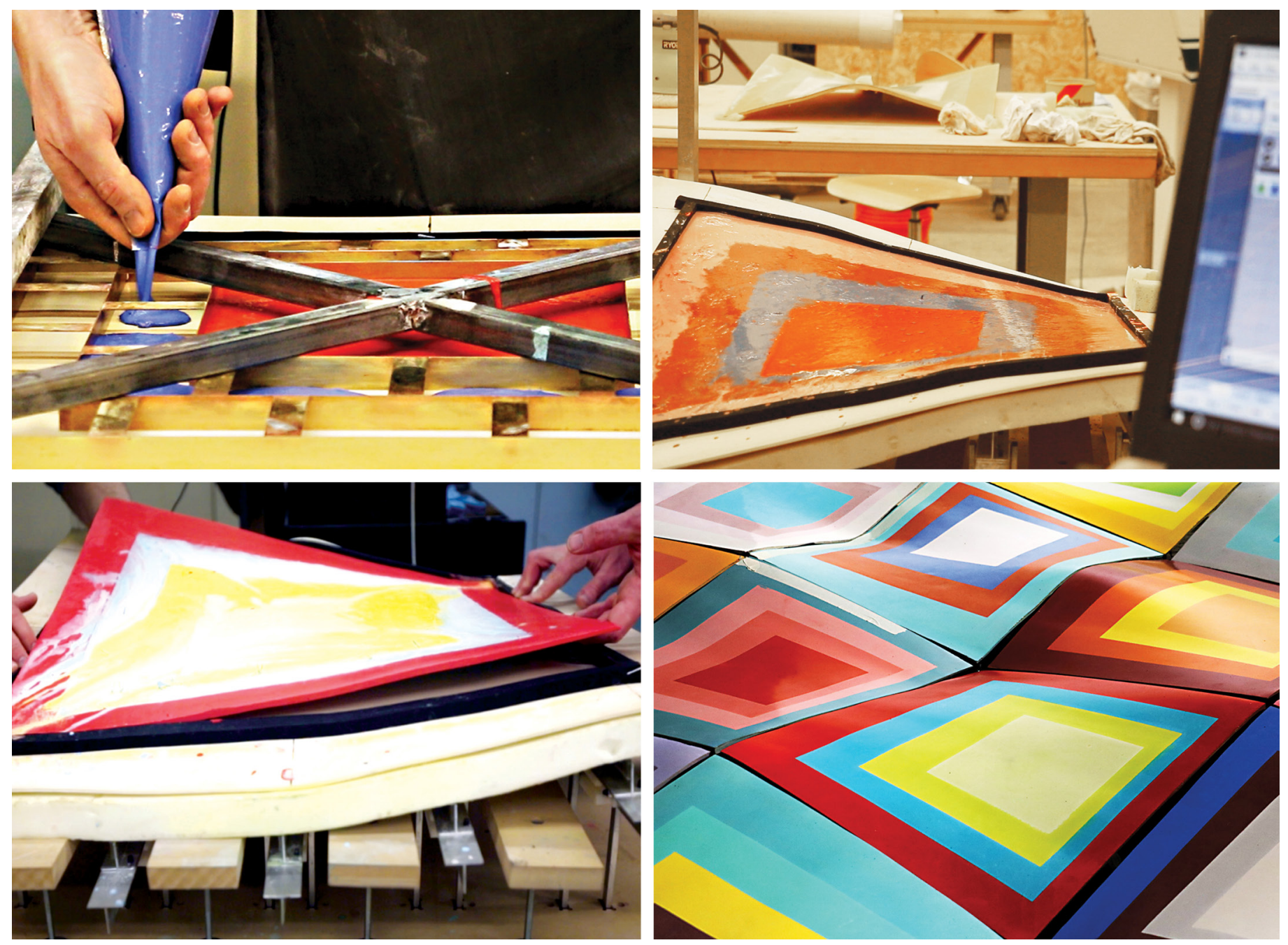

Figure 3: Digital hand-made tile process and dynamic formwork. (Morcillo Pallares, Rule, 2016)

transforming the geometrically rigid mold into a dynamic digital version and by reducing the amount of material needed, we were able to modify the tile's scale and geometry while introducing a chromatic pattern into the cement. As a way to test the mold, we built a vertical prototype composed of seventeen tiles with eight different geometries. The vertical solution was proposed to demonstrate that a heavy material like the hydraulic cement tile didn't have to be as such. By using only the finish layer, the weight of the tile was reduced and the use of glass fiber reinforced cement (GFRC) allowed us to increase the tile from an original size of $20 \times 20 \mathrm{~cm}$ with a thickness of $2 \mathrm{~cm}$ to a tile of $60 \times 60 \mathrm{~cm}$ with a thickness of approximately $5 \mathrm{~mm}$.

The only original tool that we maintained was the secondary mold or 'trepa' which was used to separate the colors of the mosaic during the casting process. The trepa for the original tiles filled the entire mold; however, in our case we needed one that was smaller than the bed of the dynamic formwork to accommodate the different tile geometries produced when flattening the projected square. In addition, the pattern for the tiles had to be one that would allow for the margin of difference produced by the varying geometries to be absorbed by the outer ring of color.

\section{CONCLUSIONS}

Focusing on the ground plane can reveal unexpected possibilities that can reside in a surface as spatial support for architecture. The objective of the research was to revisit a technique for creating surface and reexamine the physical properties of the material, its processing and its possible intersection with new approaches to making as an opportunity to explore alternative territories for fabrication and the reinvention of artisanship in the form of 'digital hand-made' for the digital era.

Changes in the production of mosaics and other materials can be aligned with larger technological shifts; however, each transition seems to maintain that the resulting objects and materials are crafted expressions of human values as an extension of the mind through the hand, industrial machine or digital interface. This relationship became the catalyst for the subsequent experi-mental technique that hybridizes a local craft (mosaics) and a once prolific material (hydraulic cement tiles), with new trends in making through digital tooling. In the work previously described the intent was to combine the precision of the digital and its inherent flexibility with the visual and tactile quality embodied in the process of the artisanal craftsman.

The result has been the reinterpretation of a handmade process empowered by the digital, resulting in a familiar but new material. 


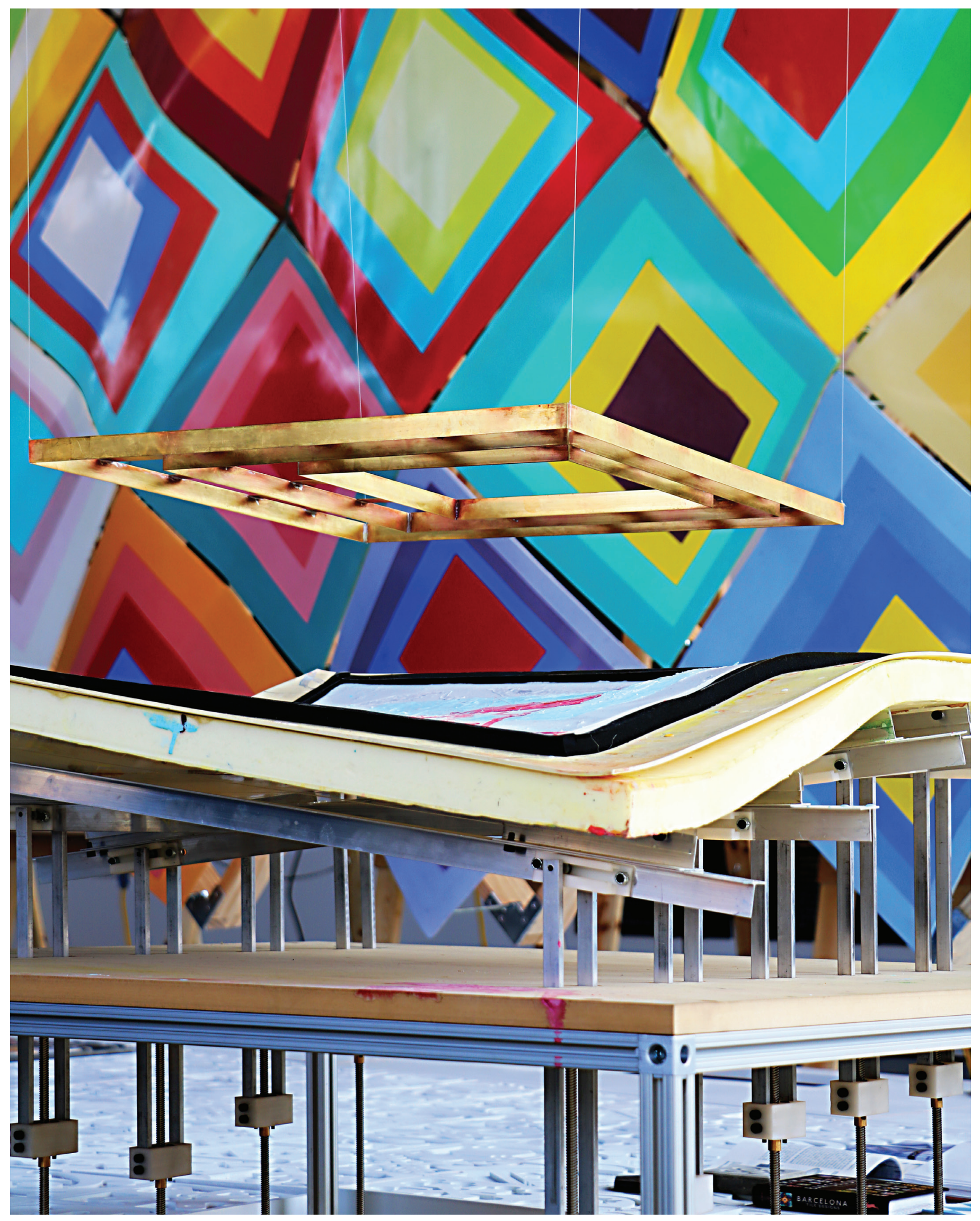

Figure 4:Dynamic formwork, brass trepa and cement panel installation.

(Morcillo Pallares, Rule, 2016) 
The hope is that this scenario of working through the reexamination of past methods of production, the handmade and the industrial, and their combination with new trends of digital production and tooling, will result in fomenting the juxtaposition of architecture, material science and programing that will allow us to challenge our expectations of form, aesthetic narrative and ultimately space.

\section{ENDNOTES}

1. Johnston, Lucy. 2015. Digital Handmade. London: Thames \& Hudson

2. Wright, Frank Lloyd. 1954. The Natural House. New York: Horizon Press

3. Adamson, Glenn. 2013. The Invention of Craft. New York: Bloomsbury Academic.

4. Johnston, Lucy. 2015. Digital Handmade. London: Thames \& Hudson

5. Fisac, Miguel. 1994. Texturas.

6. Piano, Renzo. 1969. Progettazione sperimentale per strutture a guscio - experimental project of shell structures. Casabella , 335: 38-49.

7. Adamson, Glenn. 2013. The Invention of Craft. New York: Bloomsbury Academic. 